\title{
Kinetic analysis of cardiac compression-force according to the level of information provision in the cardiopulmonary resuscitation
}

\author{
Seung-Hyun Hyun, Che-Cheong Ryew* \\ Department of Kinesiology, College of Natural Science, Jeju National University, Jeju, Korea
}

The study was undertaken to investigate the change of cardiac compression force relative to levels of information provision using components of ground reaction force. Male participants of 20s-30s $(n=10)$ who was not trained on cardiopulmonary resuscitation (CPR) and used an automated external defibrillator carried out CPR using manikin on ground reaction force plate. All executed 30 times the CPR according to the levels (1-time viewing, repeated viewing, and basic life support education) of information provision and then total sample of 300 times of ground reaction force data was utilized for the analysis. Rather basic life support condition than 1-time viewing and repeated viewing in velocity of CPR showed better pattern, and executed within $15.09 \mathrm{sec}$ of total elapsed time. Also rather basic life support condition than 1-time viewing and repeated viewing in vertical compression force during re- lease phase showed better relax-ability. Rather basic life support condition than 1-time viewing and repeated viewing in ground reaction force of anterior-posterior direction during contraction phase was insignificant, and reduced compression force toward the oblique direction. Therefore CPR training should be provided as part of cardiac and exercise rehabilitation programs in range of limited scope. It is necessary to include not only definite information but also a practice course of CPR to enhance the survival rate of the cardiac arrested regardless of progressive and scientific growth of CPR fields.

Keywords: Information provision, Cardiopulmonary resuscitation, Basic life support, Manikin, Compression force, Ground reaction force

\section{INTRODUCTION}

Out of hospital cardiac arrest is a major public health problem (Ornato et al., 2010). Death rate has been increased due to unpredictable cardiac arrest regardless of progressive and scientific growth of cardiopulmonary resuscitation (CPR) fields. Global incidence of out of hospital cardiac arrest is estimated at 95.9 per 100,000 person-years (Berdowski et al., 2010). Basic CPR manual on adult, child and infant of the cardiac arrested has rather difference. Rescuer was recommended to hands-only CPR in contrast to medical emergency team including 119 rescuer performing cardiac compression and artificial respiration simultaneously (Berg et al., 2010).

It recommended that the order of compression-airway-breath- ing should be kept in case of the adult cardiac arrested and then position of CPR be located at $1 / 2$ point from the very bottom of rib (Cha et al., 2013; Qvigstad et al., 2013). Velocity of compression should be 100-120 times per minute, depth of compression be $5 \mathrm{~cm}$, ratio of cardiac compression to breathing be 30:2 (Hinchey et al., 2010; Olasveengen et al., 2009), and finally proper breathing (Beesems et al., 2013; Berg et al., 2010).

Survival rate for the cardiac arrested showed difference depending on whether CPR was performed or not, more increased 2-3 times in case of performance than was not of CPR (Swor et al., 1995). Periodical update of CPR manual and education course related to enhancing survival rate was opened. But general people have difficulty in participation of basic life support provider course due to lack of necessity on CPR education, timing to education, inconve-
${ }^{*}$ Corresponding author: Che-Cheong Ryew (iD https://orcid.org/0000-0001-9473-3990 Department of Kinesiology, College of Natural Science, Jeju National University, 102 Jejudaehak-ro, Jeju 63243, Korea

E-mail: ryew@jejunu.ac.kr

Received: January 1, 2019 / Accepted: January 23, 2019
This is an Open Access article distributed under the terms of the Creative Commons Attribution Non-Commercial License (http://creativecommons.org/licenses/by-nc/4.0/) which permits unrestricted non-commercial use, distribution, and reproduction in any medium, provided the original work is properly cited. 
nient approach, and completion of education course etc.

The quality of $\mathrm{CPR}$ was depended on airway open, compression depth and cardiac rebound, CPR duration etc. (Pantazopoulos et al., 2015). These factors might effect on cardiac compression force according to the levels of information of CPR manual, but to be approved as effect of dual imagery learning (Batcheller et al., 2000; Eisenberg et al., 1995; Lynch et al., 2005). Proper depth of cardiac compression was vertical $5 \mathrm{~cm}$, but could occur a rib fracture and injury in condition over $6 \mathrm{~cm}$ (Hellevuo et al., 2013). Thus autopsy of patient died after CPR performance was observed fracture of $13 \%-97 \%$ of rib and $1 \%-43 \%$ of sternum, rarely pneumothorax, hemothorax, pulmonary fracture, lacerated wound of aorta, spleen injury, embolism etc. (Hellevuo et al., 2013). Like this oblique and improper cardiac compression in condition of deficient information on CPR may cause secondary damage on the patient.

Though education and enlightenment on importance of CPR and risk of cardiac arrest has provided frequently, It is unclear yet whether the extent of information provision of CPR effects on cardiac compression force or not. Therefore this study was analyzed a change of cardiac compression force using ground reaction force and manikin and assumed to be difference among variances according to the levels of information provision.

\section{MATERIALS AND METHODS}

\section{Subject}

Male of 20s-30s ( $\mathrm{n}=10$; mean year, $27.00 \pm 5.12$ years; mean heights, $176.82 \pm 6.98 \mathrm{~cm}$; mean weights, $73.75 \pm 8.84 \mathrm{~kg}$ ) who was not trained on CPR participated in this study. Experiment was progressed after agreement on experimental details and approval for safety, prevention and ethics Institutional Review Board (IRB) of Jeju National University (JJNU-IRB-2017-022).

\section{Experimental procedure}

Warming-up exercise was not performed when considering unexpected occurrence of cardiac arrest. Also it was excluded procedures of safety check of the site, response verification, 119 notification, breathing verification, utilization of automated external defibrillator etc. except for only cardiac compression (Fig. 1).

All participants performed a cardiac compression using manikin (Little Anne QCPR, Laerdal, Norway) positioned on ground reaction force plate (AMTI-OR-7, Advanced Mechanical Technology Inc., Watertown, MA, USA). Then body posture kept flexed posture of knee for maximization of compression duration and

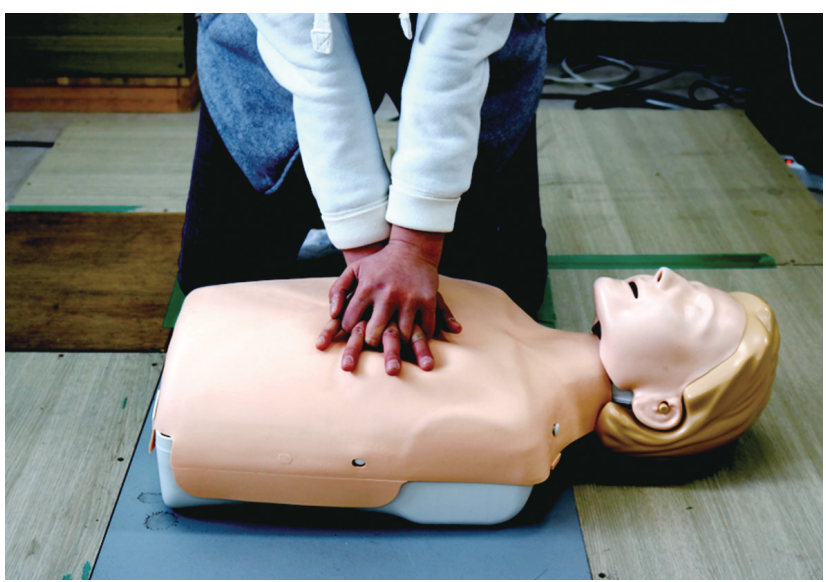

Fig. 1. Experiment field and cardiac compression.

minimization of back pain (Foo et al., 2010), and sampled at $1,000 \mathrm{~Hz}$ of ground reaction force data. Each cardiac compression was performed at 30 times $\times 5$ set (total 1,500 times), of which randomly only 1 set (total cardiac compression of 300 times) was selected for analysis (Table 1).

\section{Analysis and process data}

Ground reaction force data on the cardiac compression was monitored and stored to PC using Kwon GRF 2.0 program (Visol, Gwangmyeong, Korea). The variables selected for 30 times was consisted of compression velocity $(\mathrm{m} / \mathrm{sec})$, elapsed time (sec), and change of compression force $(\mathrm{N})$ on diastolic and systolic. Cardiac compression velocity calculated as a follow (Hyun et al., 2018). Where TT is the total elapsed time during compression, and NR as the number of repetition to cardiac compression.

Cardiac compression velocity $=60 \mathrm{sec} / \mathrm{TT} \times \mathrm{NR}$

Then TT and NR mean total time and number of repetition (30 times). Loading rate and decay rate calculated as a follow (Hyun et al., 2018; Ryew and Hyun, 2018).

Loading rate $=$ Peak vertical compression force $-\mathrm{VFO} / \Delta \mathrm{t}$

Decay rate $=V F O$ - peak vertical compression force $/ \Delta t$

Here VFO means minimum value before peak vertical force occurrence. $\Delta t$ means elapsed time during the phase.

Cardiac compression force on total 300 times was calculated for mean \pm standard deviation using IBM SPSS Statistics ver. 21.0 (IBM Co., Armonk, NY, USA). Repeated measures analysis was treated according to the levels of information provision $(\times 3)$ and post hoc: Duncan was performed in case of significant difference $(P<0.05)$. 
Table 1. Level of information provision with three types

\begin{tabular}{ll}
\hline Section & \multicolumn{1}{c}{ Information level of 3 types } \\
\hline $\begin{array}{l}\text { Type } 1 \\
\text { One time viewing: } 3 \text { min } 35 \mathrm{sec}\end{array}$ & Shout for nearby help/Get AED and emergency equipment (or send someone to do so) \\
& CPR begin cycles of 30 compressions and 2 breaths \\
& -Rate of manual chest compressions between 100/min and 120/min \\
& -Rescuers should perform chest compressions to a depth of at least $5 \mathrm{~cm}$ for an average adult, while avoiding excessive chest \\
& compression depths \\
Type 2 & Shout for nearby help/Get AED and emergency equipment (or send someone to do so) \\
Repeated viewing: unlimitedness & CPR begin cycles of 30 compressions and 2 breaths \\
& -Rate of manual chest compressions between 100/min and 120/min \\
& -Rescuers should perform chest compressions to a depth of at least $5 \mathrm{~cm}$ for an average adult, while avoiding excessive chest \\
& compression depths \\
Type 3 & Chest compressions of adequate rate \\
Basic life support education: 80 min & Chest compressions of adequate depth \\
& Allowing full chest recoil between compressions \\
& Minimizing interruptions in chest compressions \\
& Avoiding excessive ventilation
\end{tabular}

AED, automated external defibrillator; CPR, cardiopulmonary resuscitation.

Table 2. Change of total elapsed time and velocity during 30 times cardiac compression

\begin{tabular}{|c|c|c|c|c|c|c|}
\hline \multirow{2}{*}{ Section } & \multicolumn{3}{|c|}{ Information level of 3 types } & \multirow{2}{*}{$F$} & \multirow{2}{*}{$P$-value } & \multirow{2}{*}{ Posthoc(Duncan) } \\
\hline & One-time viewing $(A)$ & Repeated viewing (B) & Basic life support education (C) & & & \\
\hline Compression velocity (times/min) & $139.28 \pm 20.32$ & $125.55 \pm 14.70$ & $119.50 \pm 5.76$ & 6.821 & $0.012^{*}$ & $C>A, B$ \\
\hline Total elapsed time (sec) & $13.14 \pm 1.67$ & $14.50 \pm 1.66$ & $15.09 \pm 0.76$ & 7.900 & $0.007^{* *}$ & $C>A, B$ \\
\hline
\end{tabular}

Values are presented as mean \pm standard deviation.

${ }^{*} P<0.05 .{ }^{* *} P<0.01$.

Table 3. Change of cardiac force variables during 30 times cardiac compression

\begin{tabular}{|c|c|c|c|c|c|c|c|}
\hline \multirow{2}{*}{ Section } & \multirow{2}{*}{ Average value } & \multicolumn{3}{|c|}{ Information level of 3 types } & \multirow{2}{*}{$F$} & \multirow{2}{*}{$P$-value } & \multirow{2}{*}{$\begin{array}{l}\text { Posthoc } \\
\text { (Duncan) }\end{array}$} \\
\hline & & One-time viewing $(A)$ & Repeated viewing (B) & Basic life support education (C) & & & \\
\hline \multirow[t]{4}{*}{ Diastolic } & Medial-lateral force (N) & $-4.66 \pm 22.14$ & $-11.59 \pm 29.90$ & $-16.65 \pm 42.78$ & 0.704 & 0.508 & - \\
\hline & Anterior-posterior force (N) & $4.03 \pm 24.65$ & $-5.24 \pm 11.26$ & $8.78 \pm 21.75$ & 1.099 & 0.346 & - \\
\hline & Vertical force (N) & $68.02 \pm 37.66$ & $64.11 \pm 30.51$ & $40.94 \pm 10.58$ & 4.377 & $0.028^{*}$ & $C>A, B$ \\
\hline & Decay rate (N/sec) & $-3,001.08 \pm 584.79$ & $-2,623.65 \pm 396.76$ & $-2,735.41 \pm 480.55$ & 3.307 & 0.071 & - \\
\hline \multirow[t]{4}{*}{ Systolic } & Medial-lateral force (N) & $-4.36 \pm 25.67$ & $-16.10 \pm 30.14$ & $-17.04 \pm 34.54$ & 0.845 & 0.432 & - \\
\hline & Anterior-posterior force (N) & $-60.65 \pm 47.45$ & $-73.06 \pm 39.90$ & $-33.47 \pm 49.56$ & 5.702 & $0.017^{*}$ & $C>A, B$ \\
\hline & Vertical force (N) & $698.04 \pm 137.65$ & $663.68 \pm 96.74$ & $688.23 \pm 78.30$ & 0.707 & 0.469 & - \\
\hline & Loading rate (N/sec) & $2,943.98 \pm 804.84$ & $2,410.63 \pm 411.14$ & $2,450.18 \pm 315.60$ & 3.928 & 0.590 & - \\
\hline
\end{tabular}

Values are presented as mean \pm standard deviation.

${ }^{*} P<0.05$.

\section{RESULTS}

Sphericity assumption of Mauchly by repeated measures was satisfied by all variables $(P>0.05)$. The change of velocity of cardiac compression and total elapsed time during 30 times compression showed significant difference according to the levels of information provision $(P<0.05)$ (Table 2$)$. In variables of cardiac compression force in diastolic and systolic phase during 30 times cardiac compression (Table 3), diastolic phase showed significant difference $(P<0.05)$ in vertical compression, while systolic phase showed significant difference $(P<0.05)$ in anterior-posterior direction. 


\section{DISCUSSION}

In sport and usual life, CPR execution on the cardiac arrested occurred may increase survival rate (Schmied and Borjesson, 2014; Swor et al., 1995) when accurate CPR manual was executed. CPR data have significant implications for health services program in the fields of sports and exercise rehabilitation.

Assumption of this study, which cardiac compression force will show difference according to the levels of information provision, was satisfied partially. Of which 1-time viewing condition showed fastest velocity of compression, which was significant, and also repeated viewing condition showed over 100-120 times per minute. This result was assumed to be clear relation of 2 variables in change of total elapsed time for 30 times.

Coronary artery and brain perfusion was occurred when velocity of cardiac compression increased over 130-150 times per minute, but the increase of compression velocity resulted in decrease of compression depth, and thus quality of cardiac compression was dropped (Abella et al., 2005; Idris et al., 2012; Ornato et al., 1988). Therefore rescuer fatigued performed inefficient execution of compression force and resulted in decrease of compression depth (Foo et al., 2010). But this study was not considered that rescuer's fatigue, 1-time viewing and repeated viewing conditions which occurs an excessive velocity of cardiac compression may interrupt the consistent cardiac compression on the cardiac arrested.

When considered cardiac compression force during systolic and diastolic phase, the former showed less range in basic life support conditions than one-time viewing and repeated viewing conditions in anterior-posterior direction, and which was significant.

While vertical compression considered being core factor during cardiac compression showed more increased value in 1-time viewing conditions than basic life support conditions, repeated viewing conditions showed more reduced value. Compression load rate was influenced by total elapsed time of compression and time interval. In this view point, consistent compression load rate may be effective, but 1-time viewing and repeated viewing generated more irregular range than basic life support conditions when viewing from standard deviation. Therefore rather imagery conditions than basic life support condition not only interrupts the compression performance but also induces secondary injury when was exerted an excessive compression toward oblique direction on the cardiac arrested (Hellevuo et al., 2013).

A cardiac compression variables in medial-lateral and anteriorposterior direction according to the levels of information provision diastolic phase was not influenced. But basic life support condi- tions showed desirable vertical compression force, which showed significant difference in vertical compression force. Sufficient release at each later phase of cardiac compression can induce blood to heart (Glatz et al., 2013; Zuercher et al., 2010), but on the other hand, insufficient release of chest cause chest internal pressure to increase, thus to decrease cardiac output of blood for coronary artery and cerebral arteriosclerosis blood (Yannopoulos et al., 2005; Zuercher et al., 2010). Therefore 1-time viewing and repeated viewing conditions have limitation to transfer and understand the mechanism of diastolic force of cardiac compression in addition to characteristics related with compression time to trainee.

\section{CONFLICT OF INTEREST}

No potential conflict of interest relevant to this article was reported.

\section{ACKNOWLEDGMENTS}

This work was supported by the Ministry of Education of the Republic of Korea and the National Research Foundation of Korea (NRF-2017S1A5B5A07058707).

\section{REFERENCES}

Abella BS, Sandbo N, Vassilatos P, Alvarado JP, O'Hearn N, Wigder HN, Hoffman P, Tynus K, Vanden Hoek TL, Becker LB. Chest compression rates during cardiopulmonary resuscitation are suboptimal: a prospective study during in-hospital cardiac arrest. Circulation 2005;111:428434.

Batcheller AM, Brennan RT, Braslow A, Urrutia A, Kaye W. Cardiopulmonary resuscitation performance of subjects over forty is better following half-hour video self-instruction compared to traditional fourhour classroom training. Resuscitation 2000;43:101-110.

Beesems SG, Wijmans L, Tijssen JG, Koster RW. Duration of ventilations during cardiopulmonary resuscitation by lay rescuers and first responders: relationship between delivering chest compressions and outcomes. Circulation 2013;127:1585-1590.

Berdowski J, Berg RA, Tijssen JG, Koster RW. Global incidences of out-ofhospital cardiac arrest and survival rates: Systematic review of 67 prospective studies. Resuscitation 2010;81:1479-1487.

Berg RA, Hemphill R, Abella BS, Aufderheide TP, Cave DM, Hazinski MF, Lerner EB, Rea TD, Sayre MR, Swor RA. Part 5: adult basic life support: 2010 American Heart Association guidelines for cardiopulmonary resuscitation and emergency cardiovascular care. Circulation 2010;122 
(18 Suppl 3):S685-705

Cha KC, Kim YJ, Shin HJ, Cha YS, Kim H, Lee KH, Kwon W, Hwang SO. Optimal position for external chest compression during cardiopulmonary resuscitation: an analysis based on chest $\mathrm{CT}$ in patients resuscitated from cardiac arrest. Emerg Med J 2013;30:615-619.

Eisenberg M, Damon S, Mandel L, Tewodros A, Meischke H, Beaupied E, Bennett J, Guildner C, Ewell C, Gordon M. CPR instruction by videotape: results of a community project. Ann Emerg Med 1995;25:198-202.

Foo NP, Chang JH, Lin HJ, Guo HR. Rescuer fatigue and cardiopulmonary resuscitation positions: A randomized controlled crossover trial. Resuscitation 2010;81:579-584.

Glatz AC, Nishisaki A, Niles DE, Hanna BD, Eilevstjonn J, Diaz LK, Gillespie MJ, Rome JJ, Sutton RM, Berg RA, Nadkarni VM. Sternal wall pressure comparable to leaning during CPR impacts intrathoracic pressure and haemodynamics in anaesthetized children during cardiac catheterization. Resuscitation 2013;84:1674-1679.

Hellevuo H, Sainio M, Nevalainen R, Huhtala H, Olkkola KT, Tenhunen J, Hoppu S. Deeper chest compression - more complications for cardiac arrest patients? Resuscitation 2013;84:760-765.

Hinchey PR, Myers JB, Lewis R, De Maio VJ, Reyer E, Licatese D, Zalkin J, Snyder G; Capital County Research Consortium. Improved out-ofhospital cardiac arrest survival after the sequential implementation of 2005 AHA guidelines for compressions, ventilations, and induced hypothermia: the Wake County experience. Ann Emerg Med 2010;56: 348-357.

Hyun SH, Han JH, Ryew CC. Effect of knee positions on cardiac compression variables in cardiopulmonary resuscitation of rescuer; Manikin study. J Exerc Rehabil 2018;14:530-535.

Idris AH, Guffey D, Aufderheide TP, Brown S, Morrison LJ, Nichols P, Powell J, Daya M, Bigham BL, Atkins DL, Berg R, Davis D, Stiell I, Sopko G, Nichol G; Resuscitation Outcomes Consortium (ROC) Investigators. Relationship between chest compression rates and outcomes from cardiac arrest. Circulation 2012;125:3004-3012.

Lynch B, Einspruch EL, Nichol G, Becker LB, Aufderheide TP, Idris A. Effectiveness of a 30-min CPR self-instruction program for lay responders: a controlled randomized study. Resuscitation 2005;67:31-43.
Olasveengen TM, Vik E, Kuzovlev A, Sunde K. Effect of implementation of new resuscitation guidelines on quality of cardiopulmonary resuscitation and survival. Resuscitation 2009;80:407-411.

Ornato JP, Becker LB, Weisfeldt ML, Wright BA. Cardiac arrest and resuscitation: an opportunity to align research prioritization and public health need. Circulation 2010;122:1876-1879.

Ornato JP, Gonzalez ER, Garnett AR, Levine RL, McClung BK. Effect of cardiopulmonary resuscitation compression rate on end-tidal carbon dioxide concentration and arterial pressure in man. Crit Care Med 1988;16:241-245.

Pantazopoulos C, Xanthos T, Pantazopoulos I, Papalois A, Kouskouni E, Iacovidou N. A review of carbon dioxide monitoring during adult cardiopulmonary resuscitation. Heart Lung Circ 2015;24:1053-1061.

Qvigstad E, Kramer-Johansen J, Tømte Ø, Skålhegg T, Sørensen Ø, Sunde $\mathrm{K}$, Olasveengen TM. Clinical pilot study of different hand positions during manual chest compressions monitored with capnography. Resuscitation 2013;84:1203-1207.

Ryew CC, Hyun SH. The contribution analysis of knee compression bandage and arm swing control on maximum horizontal distance in standing long jump. J Exerc Rehabil 2018;14:239-243.

Schmied C, Borjesson M. Sudden cardiac death in athletes. J Intern Med 2014;275:93-103.

Swor RA, Jackson RE, Cynar M, Sadler E, Basse E, Boji B, Rivera-Rivera EJ, Maher A, Grubb W, Jacobson R, et al. Bystander CPR, ventricular fibrillation, and survival in witnessed, unmonitored out-of-hospital cardiac arrest. Ann Emerg Med 1995;25:780-784.

Yannopoulos D, McKnite S, Aufderheide TP, Sigurdsson G, Pirrallo RG, Benditt D, Lurie KG. Effects of incomplete chest wall decompression during cardiopulmonary resuscitation on coronary and cerebral perfusion pressures in a porcine model of cardiac arrest. Resuscitation 2005;64:363-372.

Zuercher M, Hilwig RW, Ranger-Moore J, Nysaether J, Nadkarni VM, Berg MD, Kern KB, Sutton R, Berg RA. Leaning during chest compressions impairs cardiac output and left ventricular myocardial blood flow in piglet cardiac arrest. Crit Care Med 2010;38:1141-1146. 